WellBeing International

WBI Studies Repository

$9-1998$

\title{
Evolution and Animal Welfare
}

Marian Stamp Dawkins

University of Oxford

Follow this and additional works at: https://www.wellbeingintlstudiesrepository.org/assawel

Part of the Animal Studies Commons, Other Animal Sciences Commons, and the Other Anthropology Commons

\section{Recommended Citation}

Marian Stamp Dawkins, "Evolution and Animal Welfare," The Quarterly Review of Biology 73, no. 3 (Sep., 1998): 305-328. DOI: https://doi.org/10.1086/420307

This material is brought to you for free and open access by WellBeing International. It has been accepted for inclusion by an authorized administrator of the WBI Studies Repository. For more information, please contact wbisr-info@wellbeingintl.org.

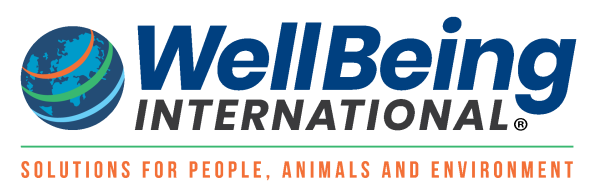




\title{
EVOLUTION AND ANIMAL WELFARE
}

\author{
Marian STAMP Dawkins \\ Department of Zoology, University of Oxford \\ Oxford, OX1 3PS United Kingdom \\ E-MAIL: MARIAN.DAWKINS@ZOOLOGY.OXFORD.AC.UK
}

\begin{abstract}
Animal welfare is a topic often thought to reside outside mainstream biology. The complexity of the methods used to assess welfare (such as health, physiology, immunological state, and behavior) require an understanding of a wide range of biological phenomena. Furthermore, the "welfare" of an animal provides a framework in which a diversity of its responses can be understood as fitness-enhancing mechanisms. Different methods for assessing animal welfare are discussed, with particular emphasis on the role of an animal's own choices and reinforcement mechanisms. No part of biology is as yet able to explain consciousness, but by confronting the possibility that nonhuman animals have conscious experiences of suffering, animal welfare studies force a consideration of even this hardest problem of all biological phenomena in a particularly direct and evolutionary way.
\end{abstract}

\section{INTRODUCTION}

$\mathrm{H}$ OW CAN THERE be a scientific study of animal welfare? If "welfare" just means "health," then isn't animal welfare simply veterinary science or animal health studies under another name? And if animal welfare goes beyond this and tries to take on mental as well as physical suffering, how can it be more than an unscientific collection of assumptions-impossible to test-about what animals might or might not be feeling?

The intent of this article is to show that animal welfare, far from being a fringe activity outside mainstream biology, could potentially be at the heart of biological thinking about fitness-enhancing mechanisms in a variety of disciplines. Assuming that "welfare" includes not only current health status but also a variety of behavioral, physiological and immunological indications that health status is likely to change for better or for worse in the future. I shall argue that many of the so-called "indicators" of welfare that have been put forward are best seen as evolutionary adaptations, either enabling the animal to counteract a threat to its health and fitness or, in the unnatural environments in which humans often keep animals, showing that the animal has failed in its attempts to do so. An action or physiological response that is effective in the wild may become pathological and counterproductive within the confines of a cage. One of the reasons why so many problems have been encountered in the study of "welfare," "stress," "suffering" and related concepts is because animal welfare studies have generally lacked the evolutionary framework that characterizes so much else in biology. Animal welfare, in other words, needs a dose of Darwinian medicine (Nesse and Williams 1995).

Before this treatment can be administered,

The Quarterly Review of Biology, September 1998, Vol. 73, No. 3

Copyright (C) 1998 by The University of Chicago. All rights reserved.

0033-5770/98/7303-0002\$2.00 
however, it is necessary to distinguish three types of questions that are often raised about animal welfare, but are almost equally often confused. The first one is, what objective measurements-biochemical, physiological, behavioral-should we use to evaluate whether the welfare of an animal is poor or good. As discussed below, biochemistry, physiology and behavior are all respectable scientific disciplines, and there is no real problem about using them in animal welfare studies. Their use might be controversial and their interpretation may be subject to doubt in some circumstances, but their scientific credentials are not.

The second type of question is, however, more difficult. Are animals that can be shown to have these objectively measured symptoms consciously experiencing what humans would call suffering, if we were experiencing these same symptoms? For example, if a nonhuman animal shows clinical signs of exhaustion, and these are comparable to those that give rise to very unpleasant experiences in humans, are we justified in concluding that the animal is also suffering? This kind of question poses more problems than the first one because it touches on the greatest remaining mystery in biology - that of conscious experience. Determining if an organism is conscious or not raises difficulties of a different order of magnitude from finding out whether a particular treatment results in a raised hormone level, for instance. Despite the avalanche of books that has recently appeared on the subject of consciousness (e.g., Dennett 1991; Edelman 1992; Crick 1994; Penrose 1994; Weiskrantz 1997), we have not achieved the same level of understanding about consciousness as we have (through objective measurements) about hormones and behavior. Insofar as it concerns itself with conscious experiences of suffering in animals, the study of animal welfare could be accused of straying off the straight and narrow path of what is strictly scientific.

Yet, when people express a concern about animal welfare, it is precisely the conscious experience of suffering that worries them most. Animal welfare has a higher moral profile than, say, plant welfare, because more people believe that animals consciously suffer than believe that plants do. Orchid growers may be concerned about the health and growth of their plants in the way that dog owners care about that of their pets, but it is the belief that animals have something extra-a mental capacity for experiencing pain, thirst, boredom and other mental states-that gives animal welfare its moral edge (Duncan 1993). This argument is also reflected in the scientific literature, where it has been held that "suffering" includes mental suffering (Dawkins 1990; Webster 1994), and even that suffering does not occur unless there is a conscious experience (Duncan 1993, 1996; Duncan and Petherick 1991).

Animal welfare is thus left with a serious problem. If it sticks to what is scientifically observable, it leaves out what distinguishes for many people the study of "welfare" from the study of physical health, namely, conscious experiences of suffering and well-being. On the other hand, if it accepts that conscious experiences (such as those humans call fear, pain and frustration) are also sensed by other species, it runs headlong into the problem of studying conscious experiences that no field of science, despite many attempts, has yet come to grips with.

The third type of question that can be asked about animal welfare arises out of a concern for animal suffering, but is logically distinct from the issue of whether animals suffer (Stafleu et al. 1996; Fraser et al. 1997). Is it ethically right or wrong to treat animals in certain ways? Tannenbaum (1991) argued that scientific studies of animal welfare can never be undertaken separately from an ethical framework. Rollin (1995) even argues that it is a waste of time to ask whether an animal is suffering, and the only justifiable approach is always to work toward reducing suffering. "Animal welfare" is therefore put into the same category as "public health": it is assumed to be a goal toward which everyone should be working. The view I shall take here is that mixing ethical questions about how animals ought to be treated with factual questions about welfare is likely to lead to confusion, since humans do not automatically know what conditions are best for the welfare of animals. Facts alone, without preconceived moral views, could lead humans to take a different view of how animals ought to be treated (Dawkins 1980). In any case, the general view that scien- 
tific and ethical questions (what "is" and what "ought to be") are different and should not be confused, has much to be said for it (Broom and Johnson 1993).

I propose, therefore, to keep these three types of questions - the symptoms of good and poor welfare, the conscious experience of suffering, and our ethical attitudes toward animals-in their own reasonably watertight compartments. Here I shall concentrate on the first question, by describing the various indicators and symptoms of animal welfare that are now in use, and how they should be seen in an evolutionary context. I shall then briefly examine the connection between what we can observe and what perhaps can infer about conscious experiences in other species. The moral implications of welfare studies I shall leave firmly alone, allowing readers to decide for themselves what they should do with the facts that are now available.

\section{Measuring Welfare In Animals}

The two big challenges in the measurement of animal welfare have been to define what is meant by welfare, and to decide how to measure it (e.g., Dawkins 1980; Curtis 1987; Gonyou 1993; Mason and Mendl 1993; Moberg 1993). In fact, the pursuit of "measures of welfare" has become something of a Holy Grail. As Fraser (1995) has pointed out, however, many of the difficulties in defining and measuring welfare have arisen because of mistaken notions about the "welfare" concept. It is not a simple variable, like the height of building, that can be easily measured in meters or feet. On the contrary, it is a complex attribute, more like the "safety" of a building rather than its height. Just as we do not expect to be able to measure the safety of a building by some single quantitative expression that will be valid in all respects and under all circumstances, so we should not expect to arrive at a measure of welfare except as a trait having multiple attributes and being different under various circumstances.

While it is now generally recognized that no single measure of welfare is adequate on its own (Dawkins 1980; Mason and Mendl 1993), there is still disagreement on how different measures should be put together and which ones should be given priority, and there is a persistent tendency to believe that a good measure of welfare (with multiple attributes if necessary) is attainable if we only knew how to construct it. In this section, I shall first review the main component measures of animal welfare that are currently in use. I will emphasize the strengths and weaknesses of each, as well as the importance of taking a broad view of what constitutes good welfare. I shall then argue, however, that the goal of animal welfare studies should not be to put the various constituent parts into a single measure, or to assign various values to different measures and then add them up to arrive at a total welfare score. Rather, I shall argue that many of the so-called symptoms of poor welfare are in fact evolutionary adaptations, that is, defenses against threats to fitness. Some defenses (such as pain and fear) are "unpleasant by design" (Nesse and Williams 1995:26) in the sense that they temporarily reduce well-being but enhance health and reproduction in the long term. Such a viewpoint has a profound effect on what we should conclude about the welfare of an animal.

\section{GOOD AND POOR WELFARE}

Injury, disease and death are the obvious veterinary symptoms of poor welfare. A widespread consensus both within and outside biology is that good welfare, at the very least, means that animals are free from debilitating diseases, injury and malnutrition, and that they are not kept in conditions that lead to the development of physical deformities (Wolfensohn and Lloyd 1994; Fraser 1995). Sometimes the first signs of poor welfare are detected intuitively by a pet owner or a livestock owner, or can be assessed quantitatively by looking at such indicators as posture, body weight, or whether the eyes are open (Morton and Griffiths 1985). At other times, injuries or deformities may be apparent only after death, as with bone breakages (Gregory and Wilkins 1989) or some skeletal asymmetries (Møller et al. 1995). There are often good practical reasons for making sure that symptoms of disease and injury are alleviated or avoided: animals kept in conditions where they are subject to infections or injuries are more likely to die, and thus fail to produce the meat, eggs or milk that are commercially valuable. But it should not be assumed that commercial pressures will 
always lead to the avoidance of even these gross measures of poor welfare. The productivity of a farm that produces eggs may be greater if birds are kept under conditions in which some of them were injured rather than if conditions were improved (at some considerable expense) so that injury rates were lower. Such gross welfare measures should be made at the level of the individual animal, not the farm unit. We should not assume that a productive farm is one where the welfare of animals is guaranteed.

Disease, injury and other clinical signs of illhealth are indicators of poor welfare for two reasons. First, they show that the animal is more likely to die. Second, they indicate that the animal's own defense mechanisms may have been activated, and these may be extremely unpleasant in their own right. For example, it is now widely accepted that pain serves a number of important functions including the avoidance of dangerous situations and simply keeping damaged limbs immobile while they heal (Wall 1979; Bateson 1991). This means that an injured animal has reduced welfare both because its injury makes death more likely (through infection and vulnerability to predation) and also because its adaptive mechanisms for dealing with injury (making death somewhat less likely in the long term) include highly unpleasant sensations of pain. Pain evolved because, by being unpleasant, it keeps us away from the larger evolutionary disaster of death. Pain is part of a mechanism for helping us to avoid immediate sources of injury, and also to refrain from repeating actions that have resulted in damage.

This distinction between poor welfare due to injury and disease per se, and poor welfare owing to the animal's own mechanisms for dealing with injury and disease, has important implications for assessing the welfare of animals that are free of disease, uninjured and, in the opinion of a veterinarian, in good health. One view is that such animals must be in a state of very good welfare indeed, and could not possibly be suffering. The other view is that they could be suffering if their defense mechanisms for avoiding disease and injury had already been activated. For example, although pain results when an injury occurs, fear is also one of the injury-avoiding mechanisms that ani- mals have evolved; it comes into play before a physical injury happens. In fact, by causing an animal to flee or hide, fear probably evolved and reduced the likelihood of physical injury occurring at all. Just as pain helps to avoid death, fear helps to avoid pain. Natural selection has led to mechanisms that operate earlier and earlier, long before health and fitness are actually threatened. Thus these unpleasantby-design, death-avoiding mechanisms come into play not just when death is imminent, but sometimes long before death is likely to occur. In other words, there may be preclinical or subclinical changes in response to a potential threat, even when the health of the animal is apparently good. It is therefore important to consider other measures of welfare besides the obvious ones of overt disease and injury, even though these are generally considered to be the cornerstone of all good welfare assessment.

\section{BEHAVING "NATURALLY"}

Over 30 years ago, Thorpe $(1965,1969)$ argued that the ability to perform natural patterns of behavior was an important criterion of welfare. He believed that preventing animals from carrying out their "natural instinctive urges" (1965:79) inevitably led to poor welfare. For example, small bare cages that do not allow chickens to scratch, dustbathe or show other behavior patterns that they normally would in "natural" systems were, he argued, inevitably detrimental to welfare.

The idea that the welfare of animals can be judged by the extent to which they are able to perform their natural behavior patterns is widespread (e.g., Kiley-Worthington 1989). It has become written into the legislation of various countries. For example, in Germany, the Animal Protection Act (1972) required that anyone keeping an animal should "provide accommodation which takes into account its natural behavior." The U.K. Farm Animal Welfare Council has stressed the importance of the "Five Freedoms," which include the freedom to express normal behavior. The current enthusiasm for "environmental enrichment" programs in zoos (Markowitz 1982; Carlstead 1996) rests on the assumption that the more of its natural behavior patterns an animal is allowed to show, the better its welfare must be.

Although humans may like to see animals 
behaving in natural ways, it is important to ask whether the animal's welfare is genuinely improved by such supposed enrichment. When we think critically about this issue, it becomes clear that there is no necessary connection between the naturalness of behavior and good welfare. For example, domestic and zoo animals show on average less escape and antipredator behavior than wild ones, but it would be incorrect to argue from this that the welfare of captive animals therefore must be lower because of the "deprivation" of not having to flee from predators (Dawkins 1980; Baxter 1983). If this were true, then environmental enrichment programs should include a regimen of frightening them by exposing them to their predators. On the other hand, it could equally well be argued that the welfare of captive animals is actually better than that of their wild counterparts, since the protection offered by captivity and the domestic environment means that they are less likely to experience fear, or injuries that might be sustained by escaping from a predator's attack. In order to settle the issue one way or the other, we need more evidence. The naturalness of an animal's behavior is no guarantee of either good or bad welfare. At most, a comparison of the behavior of a captive animal with that of its wild counterparts can only alert us to the possibility that poor welfare may result from inability to perform certain behaviors.

There is no simple link between "deprivation" of a natural behavior and welfare because various behavior patterns are controlled in different ways, which means that there will be a variety of results when captive animals are prevented from performing behaviors seen in wild animals. There is an important distinction between the two ways that behavior can be brought to an endpoint.

In some cases, a whole sequence of behaviors can be terminated when an animal achieves a particular goal or endpoint. For example, female great golden digger wasps (Sphex ichneumoneus) dig burrows in which they lay their eggs. Each burrow consists of a main shaft (which the wasp digs first) with a lower side tunnel that branches off. Brockmann (1980) showed that, if she artificially lengthened the main shaft in the early stages of construction so that it was much deeper than the wasp had dug herself, the wasp would switch to digging the side tunnel much sooner. In other words, it was the end result-in this case a shaft of a certain length-that was important, not whether the wasp had performed a certain amount of digging behavior. There are other cases, however, such as nest building in hens, where behavior seems to be much less controlled by endpoint and much more affected by performance. Hughes et al. (1989) gave hens either preformed nests (previously built by the same hen) or flat litter surfaces. Nest-building behavior was not inhibited by a nest already built, and the hens went through nest-building behavior even though a nest was already present. Nest building thus seems to be an example of where the "behavior itself is a potent source of reinforcing stimuli" (Herrnstein 1977).

Unfortunately, there are no general rules for predicting whether a given behavior pattern per se will be important to the captive animal or rendered unnecessary by providing the right environmental stimuli; therefore, there is no way, without doing specific experiments, of inferring what the results will be in a captive animal that does not demonstrate those behaviors. In nature, functional results (such as replenishing food reserves, building nests, finding water) can be achieved by a variety of mechanisms. If, in nature, a given species chases its prey for a long distance before eating it, there is no a priori way of knowing whether the animal is motivated to chase even when provided with adequate food. Behavioral ecologists have been much more concerned with functional considerations of what animals do and much less concerned with the mechanisms by which they achieve them. We are in great need of a return to the ethological balance of asking questions about both function and mechanism (Tinbergen 1963), as well as seeing the connections between them but realizing that they need different sorts of answers (Duncan 1995). The actual mechanism by which a behavioral sequence is controlled, and consequently the effects of keeping an animal in conditions where it cannot perform the behavior, are only discoverable by empirical tests. Only when we understand the mechanism of control and the behavioral and physiological consequences that result from animals being 
prevented from carrying out such behavior will we be able to decide whether departures from what is natural are good or bad for an animal's welfare. This will probably be a rather painstaking and in some ways tedious task, as the same questions will have to be asked about different species and about different behaviors within the same species.

Such considerations of "deprivation" and welfare in nonhuman animals also apply to our own species of course. We live unnatural lives in the sense that we fail to show many former behaviors in what has come to be called the "environment of evolutionary adaptedness" or EEA (Nesse and Williams 1995). Some of these "deprivations" (such as too little exercise) result in poor welfare, whereas others (such as better temperature control in our environments) have enhanced welfare. Taken alone, the degree of unnaturalness in our lives is a poor guide to the assessment of our own welfare. We need other criteria to help in that decision, both for ourselves and for other species.

\section{LONGEVITY, REPRODUGTIVE SUGGESS}

\section{AND FITNESS}

One solution that has been proposed to the problem of whether an animal's welfare is adversely affected by being unable to perform certain kinds of behavior is to measure its longevity. Hurnik (1993) has argued that not only can longevity be objectively quantified but it is also a direct readout of an animal's welfare, since it will be a measure of how well its various biological "needs" have been satisfied. He argues that the more adequately its needs are satisfied, the greater its welfare and the longer the animal may be expected to live.

The main problem with this approach is that, as Fraser and Broom (1990), Fraser (1995) and others have pointed out, animals have been selected to reproduce, not just to live a long time as individuals. A consequence of gene level selection is that the health, longevity and even survival of individual animals may be reduced in the interests of gene propagation. A very obvious example of this is the considerable costs, including reduction in physical health, that occur in animals during the breeding season. Not only do male animals often sustain serious injuries by fighting and loss of conditioning through failing to feed (e.g.,
Clutton-Brock et al. 1982), they may also suffer depression of their immune function as a result of the high levels of testosterone (Grossman 1985; McCruden and Stimson 1991). Female junglefowl lose up to $17 \%$ of their body weight while incubating eggs. Normally, such a weight loss would be viewed as a deterioration of physical health and a decline in welfare. The birds, however, appear to have been selected to be anorexic during this period, since they do not eat even if offered food while sitting on the nest (Sherry et al. 1980).

The fact that individual animals may choose to sacrifice their own welfare (as judged by susceptibility to disease, injury, and failure to perform individually essential behavior such as feeding) means that longevity of the individual may not be the most reliable criterion of overall welfare. This in turn might suggest that the welfare of animals should be judged by their reproductive success-a conclusion that would obviously find favor with farmers who seek high egg production or large litters of piglets-or their fitness (Broom and Johnson 1993). But even this conclusion could be in error. Selection does not necessarily favor maximal reproduction or even reproduction at all, as is shown by the sterile workers found in eusocial insects and naked mole rats (Jarvis et al. 1994) as well as delayed reproduction in many bird species (e.g., Emlen and Wrege 1989).

Furthermore, while loss of fitness may be a useful measure in conservation, such as in judging adverse effects of tourism on wild populations (Hofer and East 1998), it could be positively misleading in the more artificial environment of a commercial farm. Here "fitness," as defined by reproductive success, could be the result of selective breeding (or genetic modification) that is quite incompatible with good welfare. For example, a cockerel of a broiler breed might sire a large number of offspring and thus be said to have higher fitness than a barnyard cock with a much smaller number of surviving offspring. It does not follow, however, that the broiler cock, kept permanently on low light and restricted food, was in a better state of welfare, because the large number of offspring could have been achieved despite its compromised health. In an extreme case, an unhealthy bird could have been stripped of sperm and its large number of offspring attained by artificial insemination. 
Once again, although we have a measurement we can use, additional criteria are needed before we can draw valid conclusions about welfare. One of the most widely used, most quoted and most misunderstood are a suite of physiological variables collectively known as "stress" symptoms.

\section{STRESS: PHYSIOLOGICAL SYMPTOMS OF POOR WELFARE}

Even before overt signs of disease, injury or physical deformity are noted, it may be possible to detect internal signs of disturbance of metabolism that, if allowed to continue unchecked, might lead to visible symptoms of ill health that are generally agreed to indicate poor welfare (Moberg 1987). Animal welfare studies would thereby have the same objective basis as veterinary medicine, but with the added bonus that since it is concerned with subclinical or preclinical signs of ill health, the welfare of even apparently healthy animals can be assessed. Two major problems remain for such a "litmus test" of animal welfare: what physiological variables should be used, and what level of a given variable should correspond with suffering or otherwise give rise to concern for the animal's welfare.

The first of these problems- the physiological variables to look for-has largely been tackled by referring to a suite of so-called "stress" symptoms. Unfortunately, there has been a great deal of confusion both about the meaning of stress and about the interpretation of the variables that are supposed to reflect its presence (Archer 1979; Rushen 1991; Broom and Johnson 1993; Moberg 1993; Weipkema and Koolhaas 1993; Sapolsky 1994; Toates 1995). Originally the term was applied to the group of adaptive responses that many animals show when faced with a situation requiring some sort of immediate action, such as fleeing from a predator or fighting off a rival (Cannon 1929). Some of these responses, such as deeper breathing and increased heart rate, obviously prepare the animal for an action to come by delivering oxygen more quickly to the tissues that need it. Others, particularly the activation of the HPA (hypothalamic-pituitary-adrenocortical) system involve corticosteroid hormones that affect the metabolism of glucose, both by lowering its transport into cells and by inhibiting production of insulin. As a consequence, the amount of plasma glucose is increased providing immediately available energy. This energy helps prepare the body for fast and possibly prolonged action, such as fighting or fleeing from a predator. Selye (1956) called this whole set of symptoms the GAS or General Adaptation Syndrome, and he believed that one of the very striking things about it was that the reactions of the body were very similar when exposed to a wide range of different stimuli such as electric shock, cold or injury. In Selye's view, "stressors" were stimuli that could be demonstrated to trigger this syndrome. "Stress" symptoms, and in particular a rise in glucocorticoid levels, were thought to be a clear indication of a wide range of unpleasant or aversive states, and thus of great importance in the assessment of animal welfare (Barnett and Hemsworth 1990; Broom and Johnson 1993).

A number of serious conceptual and factual problems, however, have subsequently arisen that cast doubt on the universality of glucocorticoids as "stress" hormones and thus measures of poor welfare. The stress response to different so-called stressors may not be as similar as once thought, the apparent similarity resulting from a common reaction to being tested and handled (Dantzer and Mormède 1983; Moberg 1993; Rushen and De Passillé 1992). Even more serious, higher glucocorticoid levels (as well as increased heart rate and other symptoms of stress) occur in situations that could be considered very pleasurable, such as during sexual behavior, feeding behavior or anticipation of food (Szechtman et al. 1974; Colborn et al. 1991).

This generality of the stress response observed in situations regarded either as pleasant or as unpleasant has caused much confusion. Despite many attempts to strip the stress response of its negative connotations, such as Selye giving one of his books the title Stress without Distress (1974), the word stress in popular usage continues to imply something unpleasant, damaging and definitely to be avoided if at all possible. A more neutral word such as "arousal," "excitement" or "physiological activation" would not bias an answer to the question of whether a particular instance of the GAS was positive or negative, but when 
corticosteroids are labeled "stress" hormones, many immediately are led without thinking to the conclusion that if some activity causes a rise in "stress hormones" it must, by definition, be bad for the animal's welfare. Indeed Broom (1991), in discussing elevated corticosteroid secretion in domestic animals that are handled, argues that "a greater response indicates poorer welfare than a smaller response."

Recently, even more confusion has crept into the literature. The word "stress" has been used to cover not only physiological responses involving increased glucocorticoid secretion but also any negative effect whether it is mediated through corticosteroids or not. Thus, in a variety of animals, it has now been shown that symmetrical individuals are more attractive as mates than ones that are asymmetrical (Møller and Swaddle 1997). Symmetry, such as shown by the ability to grow two horns or two tail feathers of the same length, is believed to be an indicator of mate quality because symmetry is difficult to achieve in the face of perturbations in the environment (Parsons 1990). Animals that have enough resources to achieve symmetry are thus thought to be of higher quality. Perturbations that can potentially disrupt developmental processes are unfortunately referred to as "stressors," even though there may be no evidence that corticosteroids are involved at all.

The inexorable (but misleading) logic about stress now goes like this: Stress was originally defined as any factor which leads to increased corticosteroid secretion. In popular thinking, however, stress implies something unpleasant and bad for welfare. Therefore any increase in corticosteroid levels must be bad for welfare and that in turn must be stressful, regardless of whether it leads to increased corticosteroid levels. Put in this light, it is easy to see that the confusion about the word "stress" is considerable and is made up of several different sources of error.

The solution that Toates (1995) proposes is not to abandon the concept of stress altogether, but to refine the definition in such a way that elevated corticosteroids becomes a necessary but not a sufficient condition for calling something a stressor. The extra element he proposes is that elevated corticosteroid levels should be shown to occur in condi- tions that the animal finds aversive (and will attempt to avoid), thus giving a critical role to the animal's own response to the situation, a point we will return to later.

The advantage of this viewpoint is that it allows us to get around the realization that highly pleasurable situations can also give rise to elevated corticosteroid levels (a kiss is not stressful; the presence of a predator is). The disadvantage is that the word "stress" has now become so widely used in situations where no one has even looked for corticosteroids (such as in many current studies on fluctuating asymmetry) that even this understanding may not be enough to stem the tide of confusion. Furthermore, an evolutionary approach to the way animals respond to potentially damaging situations gives us yet another reason why "stress," even when restricted to demonstrably aversive situations in which there is known to be a rise in corticosteroid levels, may not be the best or most useful way to forge the link between physiology and measures of poor welfare.

Even a very simplistic Darwinian starting point would lead us to expect that animals would behave and respond physiologically in adaptive ways in the face of threats to their survival and reproduction. But it would be extremely implausible to suggest that all such threats would be met in the same way. For example, if an animal's life and well-being are being put at risk by dehydration, we would not expect it to respond in the same way as if it were threatened by an approaching predator or to the danger resulting from having a broken limb. Seeking water, running away from a predator, or remaining immobile to prevent further damage to an injury are all adaptive responses, but it is clear that they are all different. Some animals respond to predator attack by fleeing, others by freezing and remaining motionless. It is therefore not surprising to find that the physiological responses that accompany and give rise to these disparate behaviors would also be different (Freeman 1985). The fact that the physiological "stress" response occurs after such a wide variety of different stimuli, such as injury, cold, and disease, is quite remarkable.

But the fact that some diverse stimuli give rise to a common "stress" syndrome does not necessarily mean that all threats to survival will 
do so. We must go back to the considerations of why the "stress" response occurs at all. As we have previously seen, stress prepares the body for action by making it ready for "flight or fight." It follows that threats to the animal that are not met most adaptively by intense activity might not be accompanied by a "stress" response at all, yet could still be highly aversive to the animal. Indeed, we find some animals that respond to predators by remaining immobile do not show the "stress" response. They do not need the increased energy that glucocorticoids provide and a pounding heart might actually make them less immobile and thus more in danger of being spotted (Gabrielsson et al. 1977).

A similar argument holds between different threats posed to the same animal. If the welfare of an animal is threatened by a predator, it may well need to prepare for action, but not if its welfare is being compromised by a lack of stimulation. For this reason, simple comparisons between levels of corticosteroid hormones in two situations can be extremely unreliable guides to the welfare of animals. In laying hens, a comparison is sometimes made between caged birds and those kept in larger groups or range freely. The threats to freerange birds (predators, interactions with large groups of other birds), however, are quite different from those of caged birds where lack of freedom to turn or the absence of nest boxes could be expected to give rise to a different set of physiological and behavioral responses. Any simple conclusion based on just one physiological stress variable is therefore bound to be suspect.

There is another evolutionary reason why we should expect "stress hormone" levels to be an unreliable guide to welfare: There is a great deal of overlap between physiological responses to pleasurable and aversive situations. Preparation for action is as characteristic of many pleasurable responses as it is of aversive ones. Both the prey that runs away from its predator and the predator that runs after it in anticipation of something to eat have to make a major physical effort and to mobilize their resources to do so. It is therefore not surprising that many of the "stress" symptoms we see in animals attempting to get away from aversive situations are also present in animals ac- tively engaged in pleasurable situations. Animals seek out and move towards food, water, mates or a comfortable nest, and they use the same limbs and muscles to achieve those goals as they do to avoid threatening situations, and they may do so just as actively. It is therefore to be expected that positive reinforcement of sexual activity will have symptoms, including increased heart rate and raised corticosteroid levels, similar to those induced by aversive or punishing stimuli.

Increased corticosteroid levels are thus not necessarily indicative of negative emotional states or poor welfare, but of more general states of excitement that can be either pleasant or very unpleasant indeed. The only difference between states we refer to as good welfare and poor welfare may be whether the animal actively attempts to go toward or away from something, that is, whether the animal finds a situation aversive or punishing. This in turn may be reflected physiologically only in minute brain differences between the two states. Agony and ecstasy may be similar except for a small crucial difference that may be very difficult to detect. What have been described as physiological measures of stress tend to be measurements of preparation for action, whereas what we really need to know is whether the decision-making mechanisms of an animal have evaluated the situation as aversive or pleasurable. Until we have a better developed physiology of decision and choice in animals, we will need to supplement our physiological measures with behavioral measures of aversion (see next section on behavior and animal welfare).

In addition to this difficulty of relying only on corticosteroids, there are other practical problems that have beset studies on "stress" responses. Rushen (1991) documents a number of studies that actually describe completely contradictory results. Corticosteroid levels in laying hens have been reported as being higher in cages than in pens (Gibson et al. 1986), lower in cages than in pens (Koelkebeck et al. 1987), the same (Craig et al. 1986) or dependent on the level of handling (Mench et al. 1986). Since quite different conclusions can be drawn about the relative welfare of birds kept in cages or in pens, depending on which study is cited, it is extremely important 
to know how such apparent contradictions arise. Some answers are not hard to find. Few studies report the effects of handling on birds whose blood is taken for sampling, and do not even state how long after being caught (itself a potential stressor) the blood samples were taken. As handling affects corticosteroid levels in the blood, it is clear that this is potentially a major source of error. There is a natural rise and fall in hormone levels that take place after a stressful stimulus has been applied (Wingfield et al. 1997) which is often not taken into account when measuring changes in corticosteroid levels after exposure to environmental stimuli.

This is not meant to imply that physiological measurements are unimportant. But it does mean that, in choosing which physiological variables to use to measure poor welfare, we should not rely too heavily on those that happen to have been labeled "stress hormones," as they may not be as specific to states of unpleasant motivation as we might have thought. Relying on conventional measures of stress without corroborative behavioral evidence that the animal is not merely excited at the anticipation of pleasurable experience can be, and indeed has been, very misleading.

Apart from glucocorticoids and their reputation as "stress hormones," a number of other physiological measurements have been used to assess welfare. These include hormones such as prolactin and luteinizing hormone, naturally occurring opioids such as $\beta$-endorphins, as well as changes in neurotransmitters such as dopamine and noradrenaline (for reviews see Broom and Johnson 1993 and Toates 1995). Particular interest has recently centered on evidence that skeletal or heart muscle has been damaged as a result of overexertion. Bateson and Bradshaw (1997) used a variety of measures to argue that red deer (Cervus elaphus) in the U.K. are in a state of physiological exhaustion and show evidence of muscle damage after being hunted with hounds, compared to nonhunted deer that had been shot with rifles. In a typical deer hunt, the animals are chased for nearly $20 \mathrm{~km}$, after which their levels of plasma hemoglobin are consistent with considerable intravascular hemolysis that is much more severe than that associated with "normal" exercise in this species. Creatine ki- nase and other enzymes also showed much higher levels in chased deer than in those that were shot. These major differences led Bateson and Bradshaw to conclude that deer hunting with hounds causes considerable suffering. As a result of this conclusion, the National Trust (a major landowner in Britain) decided to ban deer hunting on its land because of animal welfare considerations.

Suppressed functioning of the immune system has also been suggested as an important physiological indicator of welfare since it is so directly related to susceptibility to disease which, as we have already seen, is a universally acknowledged measure of poor welfare. Moreover, suppression of immune responses seems to be affected by glucocorticoids, natural opioids and other aspects of the physiological stress response (Sapolsky 1994; Toates 1995). In humans, there appears to be a demonstrated link between stressful life events, immunosuppression and disease, such as in the case of increased susceptibility to colds (Andersen et al. 1994). In mice, too, social status and hormonal state affect susceptibility to disease (Barnard et al. 1993).

There are very complex and reciprocal interactions among the nervous, endocrine and immune systems (Maier et al. 1994). The interpretation in terms of animal welfare is even further complicated because sex hormones, particularly testosterone, also suppress the immune system. Thus many male animals have an increased susceptibility to diseases and parasites during the breeding season as quite a natural part of their life cycle. Indeed, one current theory of mate choice relies on the assumption that the immune function in breeding males is inevitably compromised, and that females choose males that are able to overcome this "handicap" (Folstad and Karter 1992). Once again, we are cautioned about concluding too much from a single physiological measurement.

It is clear, then, because of the many and complex ways in which physiological factors prepare the animal to respond to threats, that it is very difficult to state which ones reliably and definitively correlate with states of suffering or pain that indicate poor welfare. That is not to say, when the studies have been done, that a physiological variable might not turn 
out to be extremely useful in the assessment of welfare; but our confidence that it can be used as such depends on extensive work that demonstrates its exclusivity to aversive situations, as shown by the behavior. Nor should we necessarily expect any one physiological variable to be seen in all situations that animals find aversive. Given that animals respond differently to various threats, we may have to be satisfied with a range of different variables, each specific to a particular aversive situation. One set of physiological variables may be good measures of suffering caused by exhaustion as a result of a deer being chased by dogs over a period of a few hours, but quite different measures may be appropriate for suffering caused by a bird being deprived of food or a farm animal being kept on a bare slatted floor for many weeks.

The second difficulty with using physiological measurements is knowing what level of a given physiological variable should be considered to indicate poor welfare. Even if one supposes that corticosteroid hormones are the appropriate variable to use for assessing a situation that the animals found aversive, we would still need to know how high the levels would have to rise before we could conclude that the animal's welfare was being adversely affected. As we have seen, corticosteroids are an important and adaptive part of the body's natural defenses against certain dangers, so that we should not conclude that any rise was necessarily indicative of poor welfare. But how much of a rise would be indicative?

This is essentially the same dilemma encountered by Nesse and Williams (1995), who try to distinguish between responses that the body makes to disease that are essentially defense mechanisms (such as fever and pain) and those that are defects (such as jaundice and ulcers). They argue that our bodies have evolved adaptive defense mechanisms, such as raising the body temperature when challenged by disease organisms, because this provides an unfavorable environment for those organisms. A fever is unpleasant for us but damaging to bacteria and viruses. Feeling ill and taking to our beds may be adaptive because it forces us to rest and thus hasten recovery. Although we may feel better temporarily if we take aspirin, reduce our fever, and carry on normally, we may in the long run take longer to recover, and in this sense reduce our welfare. On the other hand, there will be other symptoms, such as ulcers, which are nonadaptive and a sign that the body's defense mechanisms have broken down. Here finding ways to reduce pain may be the best thing to do. Since the body may not be able to repair itself, taking steps to make ourselves feel better by reducing our suffering is more likely to lead to a full recovery sooner.

The problem is that although both cases involve unpleasant feelings of illness and pain, in the first instance these indicate that adaptive defenses are at work, whereas in the second they are a sign that the defense mechanisms have broken down. Natural defense mechanisms that are "unpleasant by design" for adaptive reasons may outwardly appear and inwardly feel the same as those of a defensive breakdown. So where should the line be drawn? How much in the way of natural defense mechanisms (e.g., a rise in heart rate or corticosteroid levels) should be seen as compatible with good health and welfare? Where, in other words, does unacceptably poor welfare begin?

There is, of course, no single answer to this (Mendl 1991). The answer to the question of whether fever is adaptive in a given instance is a purely empirical one: does taking aspirin when feeling ill lead to a longer or shorter period of recovery? It is not unlike the question of whether depression in humans is a defense or a dysfunction: are people who experience depression better or worse at making important life decisions (Nesse and Williams 1995)? It follows that questions of how much fever or how much depression should be tolerated before attempts are made to reduce them are also empirical ones. We have to discover what relationship a given level of malaise has to other accepted criteria of welfare, the most obvious ones being those relating to physical health. As we have seen repeatedly, there is no way to calibrate what level of a physiological variable is compatible with good welfare just by considering it in isolation. We need either to show that the variable in question relates directly to physical health or that it is linked to it indirectly via some other pathway. 


\section{BEHAVIOR AND WELFARE}

Behavior has been used in the assessment of animal welfare in two different ways. The first is that various kinds of behavior such as stereotypies, redirected activities, and vacuum activities have been used as indicators of poor welfare, somewhat in the same way as physiological measurements. These behavioral indicators are subject to the same two difficulties that beset physiological measurements, namely, deciding which behavior to use and determining how much of a given behavior indicates "poor welfare." The second way behavior has been used is as a more direct readout of how an animal responds to a given situation, and whether the animal finds it aversive or pleasurable. We have seen in the previous section that many of the physiological symptoms that accompany pain and suffering are similar to those that accompany pleasure. Since the distinction between pain and pleasure is obviously critical to the assessment of welfare, the behavioral distinction between aversion (that is, an animal will work to get away from it) or pleasure (an animal will work to gain or continue with it) is one of the most critical ones that can be made. The animal's own choices and preferences are thus seen not merely as peripheral and perhaps sentimental luxuries that are less important than "objective" measures such as stress hormones, but rather as an indispensable part of welfare assessment, and critical to the correct interpretation of almost every other criterion. Below I will outline how behavior has been used in this first way, but then concentrate on its second and, in my view, much more critical role as the key indicator of pleasure or suffering.

\section{Behavioral Indicators}

It is assumed that poor welfare often results when animals are prevented from expressing highly motivated behavior (Dawkins 1988), either because the relevant external stimuli are absent or because the confines of a cage physically prevent them from doing so. One justification for using a particular behavior as a measure of welfare is that it indicates when an animal is highly motivated, but frustrated or thwarted in its attempts to accomplish a behavior. Alternatively, even when it might not be limited physically, there may be a conflict be- tween two strong motivations (e.g., to feed or to flee from the presence of a conspecific at the food dish), and thus an animal is effectively excluded from an important activity such as feeding. Many behavioral indicators of welfare are therefore thought to indicate frustration or conflict. For example, Tinbergen (1951) described a category of behavior shown by animals when they are in a conflict which he called displacement activities-odd or irrelevant behavior that appears to have nothing to do with the conflict at all. A herring gull in a conflict between attacking a rival and fleeing, may suddenly start pulling up grass, thereby engaging in apparently irrelevant nest-building behavior in the middle of a fight. Since there is considerable evidence that displacement activities occur in situations of conflict and tension, Maestripieri et al. (1992) suggested that such "irrelevant" behaviors might have considerable value as indicators of emotional conflict. Another indication that an animal is highly aroused is when captive animals go through complete behavioral sequences even when the usual stimuli eliciting such behavior are not present. Hens kept on wire-floored cages will go through all the movements of dustbathing (Vestergaard 1980) even though there is no loose substrate on the floor and no dust reaches the feathers. Lorenz (1950) called such behavior vacuum activities because they are performed "in a vacuum," that is, in the absence of any external releasing stimuli. To Lorenz and others who accepted his energy model of the control of motivation, the presence of vacuum activities indicated a high level of frustration, and therefore poor welfare (e.g., Sambraus 1982).

Even if it is not strictly correct to say that such behavior is elicited in the absence of all external stimuli (caged hens often flick food onto their heads and thus may gain some stimulation relevant to dustbathing), it is nevertheless true that captive animals may perform behaviors to apparently reduced levels of external stimulation. Although this may indicate a degree of frustration, it does not follow that the animal's welfare is necessarily poor, since the performance of a vacuum activity may itself be an adequate substitute for the real thing. Pet dogs chase balls, but we do not conclude therefore that their welfare is reduced 
because they may be deprived of hunting behavior. On the contrary, chasing balls seems to be highly reinforcing and generally an adequate substitute for hunting prey. Once again, as with many of the physiological measures discussed earlier, the occurrence of substitute or vacuum activities in itself does not indicate poor welfare. It should alert us to the possibility that an animal is highly motivated to behave in a certain way but, without further investigation of how that behavior is controlled and what turns it on and off, that behavior cannot lead us to conclude that the welfare of the animal has necessarily been compromised.

Even greater caution should be applied to labeling a behavior "abnormal" because it looks odd, and then assuming that all abnormal behavior is indicative of poor welfare. Some abnormal behavior, such as self-mutilations (e.g., feather plucking in parrots), are clearly an indication that all is not well, but not because the behavior is abnormal in the sense of "different from average" or even "not seen in wild animals" (Mason 1991). Rather, it is indicative of poor welfare because it results in injury, thus anchoring it firmly to the very first criterion we considered. Other abnormal behavior (in the sense of "away from the norm") may be completely compatible with good welfare. For example, the behavior of pets towards humans (and vice versa) can be extremely abnormal without any suggestion that the welfare of either party has been compromised.

There is, however, one category of abnormal behavior that has attracted a great deal of attention as an important indicator of poor welfare. Stereotypies are fixed sequences of behavior performed over and over again in the same way with no obvious function (Mason 1991; Lawrence and Rushen 1993). For example, polar bears and foxes in zoo enclosures may stand swaying their heads and necks from side to side or may pace around a set route so often that they wear away the ground. Sows confined in stalls may constantly rub their mouths back and forth over the bars, doing this so often that they make themselves bleed. The term "stereotypy" is in many ways an unfortunate one because it would seem to imply the fixed or stereotypic nature of the sequence being performed, which would include many quite natural sequences such as breathing and courtship displays. Indeed, stereotypy has in the past been viewed as an evolutionary pressure on signals to make them less ambiguous (Cullen 1966). In the context of animal welfare, however, the defining feature of a stereotypy is not just its fixed nature but its apparent lack of function. Swaying to and fro or pacing round and round a small cage does not achieve anything for the animal, and yet it continues to do it.

The causal basis of stereotypies, as well as exactly what they indicate about the welfare of animals, is a matter of continuing debate. One complication is that the early development of a stereotypy may be owing to factors different from those that maintain it in an adult animal (Lawrence and Terlouw 1993; Mason and Turner 1993). Hens in small cages may develop stereotypic pacing back and forth, apparently out of frustrated attempts to escape (Duncan and Wood-Gush 1972). Even when let out of their cages, however, they may continue to show the same stereotyped behavior. So a stereotypy may not necessarily indicate any current adverse conditions. Rather, it may indicate that at some time in the past, its welfare was compromised and that the animal is still affected by that past experience.

Another problem with the interpretation of stereotypies is that they may even help the animal cope with its environment, in the same way perhaps, that pacing up and down for a human sometimes relieves tension. There is some suggestion that stereotypies are associated with a reduction of some of the physiological symptoms of stress, such as corticosteroid levels or heart rate. Cronin et al. (1985) even proposed that by performing stereotypies such as bar-biting, pigs induce a state of selfnarcotization through the release of endorphins into the bloodstream. We should not conclude, however, that stereotypies maintain the physiological balance of the animal and thus are no cause for concern. Rather, viewing them in an evolutionary context suggests that they may be failed attempts on the part of an animal to alter its environment in some way. For example, behavior such as gnawing, pushing or running may be adaptive in the sense that they increase an animal's chances of escape in many natural situations. In a small cage where escape is impossible, however, they may 
be totally ineffective, and yet repeated over and over again by the animal, so that they appear to be functionless stereotypies, albeit with a functional origin. Repetition of behavior that does not fulfill its evolutionary role is widely believed to indicate poor welfare at some stage in the animal's life (Dantzer 1991; Broom and Johnson 1993; Mason 1993).

Still another indication of poor welfare is a change in activity levels, that is, changes in an animal's movement-either how it carries out a behavior or how long it takes to do it. Cattle kept on slatted or slippery floors may take up to 20 minutes to lie down, whereas they take only a few seconds on a nonslippery floor (Andreae and Smidt 1982), strongly suggesting considerable discomfort on the slatted floor. The unusual gait and general difficulties with standing or walking has been noted as an outward sign of bone abnormalities in intensively kept broiler chickens (Wong-Valle et al. 1993) and turkeys (Nestor 1984). More positively, since play behavior is associated with physical health (Fagen 1981; Martin and Caro 1985; Bekoff and Byers 1992) it has been suggested that the presence of this behavior should be taken as a sign of good welfare in captive animals, particularly young ones (Lawrence 1987).

The idea that an animal's vocalizations might provide an indication of its state of welfare is an attractive one. Calls are easy to record and quantify, and as communication signals they may have evolved specially to indicate "need," particularly from young animals to their parents (Godfray 1991). Weary and Fraser (1995) showed that what they called nonthriving piglets (light weight and low weight gain) and piglets that had not been fed for some time gave higher frequency calls than those from thriving and well-fed piglets. Domestic chicks give high-pitched and piercing "distress" calls when isolated or cold (Wood-Gush 1971) and the ultrasonic calls of rat pups increase when they become chilled (Olivier et al. 1994). Weary and Fraser therefore suggest that such calls can be used as measures of the welfare of a particular animal.

While such vocalizations may be extremely valuable as indicators of need in young animals, they can be expected to be confined mostly to situations where the one calling endeavors to summon the aid of another animal, such as an infant calling to its parents, or among very highly social animals that aid other members of their group.

During tonic immobility, sometimes called animal hypnosis (Eddy and Gallup 1994), animals remain absolutely motionless, notably when handled. In chickens, it consists of lying on their backs in a rigid and frozen position, but versions of "frozen" and apparently hypnotized postures are seen in a wide variety of animals. It appears to be an antipredator response when an animal is captured, and the only defense is to "play dead." The duration of tonic immobility- the time from its induction to the animal righting itself-has been used as a measure of fearfulness (Jones and Faure 1981; Vestergaard et al. 1993).

Many different behavioral indices have been proposed and certainly have their uses in the assessment of welfare, but they are subject to the same two problems that were raised in connection with physiological indicesnamely, that although they may under some circumstances indicate that an animal's welfare has diminished, their interpretation is subject to doubt; even where some impairment of welfare is indicated, it is difficult to know how much. Broom and Johnson (1993) proposed that if an animal shows stereotypic behavior more than $40 \%$ of the time, then it is suffering, but this figure is somewhat arbitrary. We still need a way of anchoring the behavioral symptoms of aversiveness of a situation to the animal, and a framework for deciding how the different constituent indicators can be linked together. I shall argue that the unifying framework is the animal's system of preference and choice.

\section{Choice, Reinforcement and Welfare}

In humans, reduced welfare results from a variety of circumstances. Exhaustion from overwork, boredom from not enough to do, fear from hearing an intruder in the house, or prolonged thirst are all unpleasant and, if protracted, likely to lead to reduced welfare, but they are all different. They result in various physiological responses and have diverse behavioral responses as well. About the only thing they have in common is they all spur us to remove ourselves from those situations, and to strive to avoid the same situations in future. 
In other words, they are all aversive, as demonstrated by our reactions. The importance of knowing whether an animal, human or nonhuman, shows by its behavior whether it finds a situation aversive becomes apparent when we observe two people riding a roller coaster. Both are screaming, both have pounding hearts and a rush of adrenaline, but perhaps one has been dragged unwillingly onto the ride and is genuinely frightened, whereas the other enthusiastically climbed aboard and is enjoying the ride greatly. Operationally, we can distinguish them by whether they freely choose to have a second ride. For the first person, the ride is clearly aversive and may have given rise to genuine suffering. For the second, it provided positive reinforcement. It has been suggested that similar logic may be used with nonhuman animals to distinguish between situations that they find pleasurable or reinforcing and those that they find aversive (Dawkins 1990).

There are two issues here. One is how an animal's choice and reinforcement mechanisms are related to health and welfare. The second is whether the subjective human experiences of "suffering" that often accompany negative reinforcement or absence of positive reinforcement (such as in pain or lack of food) are also present in nonhuman animals in aversive situations. In keeping with my intention to separate such questions, I shall here concentrate on the first and postpone discussion of the second until later, starting with a view of how animal choice and reinforcement mechanisms have evolved as part of adaptive behavioral strategies.

Natural selection has led to the evolution of some behavioral mechanisms that help ensure the survival of the body, while others favor reproductive success, even at the risk of the individual's survival. Some of these mechanisms are concerned with avoiding damage or injury to the body when the danger is already present (for example, protecting a limb from likely injury). Others are concerned with avoidance of a situation entirely when damage or injury is likely. An example of such avoidance would be moving away when a predator appeared on a distant hillside, long before a chase was initiated. Still other avoidance tactics are used even earlier in time, such as a preference for sleeping during the day in dense vegetation, when an animal is hidden from predators altogether. These are all adaptive explanations. If we look at the mechanisms by which such adaptive choices are made, however, we can posit a wide variety of possibilities ranging from simple fixed rules to a complex moment-to-moment evaluation of different outcomes.

The simplest mechanisms are tropisms and taxes in which orientation toward or away from a stimulus is achieved by linking receptors to a response mechanism. Such mechanisms are found in both animals and plants, but they tend to give rise to very fixed responses, such as movement toward light or nutrients. With many animals, however, natural selection has enabled them to respond much more flexibly through a system of positive (rewarding) and negative (punishing) reinforcers. Animals can learn responses that provide rewarding experiences associated with increased fitness, but they can also learn negative responses to stimuli associated with reduced fitness. The important point is that an animal using a system of reinforcers and learned associations will, like the simpler animal or plant with its tropisms and taxes, be able to avoid predators and find food, but will be much more flexible because it can try to take a much wider range of other responses in case of failure. It will also be able to decide between very different courses of action by weighing the reward (or punishment) value of different ones (Rolls 1990). For example, the taste of water would provide a greater reward for a very thirsty animal than a moderately sweet taste to a well-fed one. To make sure that rewards are appropriately chosen, they need to be evaluated on a similar scale that will accurately assess the costs and benefits of obtaining them at that moment (Houston and MacNamara 1988). Reward and punishment signals provide a common currency for helping an animal decide which action to take at a given time (Rolls 1998).

This has important implications for animal welfare because reinforcers may become important to the animal, quite apart from their fitness consequences. Thus, if seeking cover in nature is an important antipredator adaptation for a small mammal, and hence positively reinforcing, then such an animal in a predator-free captive environment may find that seeking cover is positively reinforcing whereas 
absence of cover is very aversive, even though its fitness in captivity is not increased by seeking cover. Its welfare could, however, be significantly reduced if no cover were provided. Indeed, I will go one stage further and argue that, apart from overt health problems, most of the concerns about animal welfare arise because of reinforcement mechanisms-that is, animals find some situations highly aversive and are unable to fulfill the conditions that are specified by their reinforcement mechanisms.

The evolution of positive and negative reinforcers that allow flexibility of behavior and the acquisition of new responses thus has a cost: animals may find certain circumstances very negatively reinforcing even when their health or fitness is not actually threatened. The caged animal kept without cover has reduced welfare by being continuously fearful even though its welfare (as judged by health and fitness prospects) are good. The means of increasing fitness in the wild (through fear that results in escape for instance) becomes part of what we then judge to be reduced welfare. It follows that good welfare involves not only good health and prospects for future health as judged by a human observer, but good welfare as perceived by the animal. If a cage without cover is perceived by the animal as highly aversive; then there is less than good welfare, even for a healthy animal.

As argued earlier, we have no a priori way of knowing what will be positively or negatively reinforcing to an animal, or even whether an animal is able to associate a specific response with obtaining or avoiding a given reinforcer. Such insights have to be established by experiment. As we have also seen, the physiological measurements that have been made so far are almost all of the activation or exhaustion of the motor side of the system, not of the decisionmaking reinforcement mechanisms themselves. Until we have brain-scan or other techniques for deciding whether an animal evaluates a given situation as aversive or pleasurable, we must rely on the behavior of the animal itself and, in particular, on its choice behavior and its ability to associate arbitrary responses with rewards and punishments.

Furthermore, we also have to establish whether a given reinforcer will cause an animal to obtain what it needs or to get away from what it finds aversive (Dawkins 1990). If the animal shows little evidence of being able to change its circumstances, then probably the change will make little difference to its welfare. But if the animal will literally "do anything" to get something it wants, or to escape from the conditions in which it is being held, the change may be very important. An animal that will push heavy weights, give large numbers of arbitrary responses (such as pecking a key or pressing a lever), cross an electric grid or otherwise give high priority to obtaining a positive reinforcer or getting away from a negative one, is demonstrating the value it places on that reinforcer. Matthews and Ladewig (1994) used the number of presses on a nose plate that pigs made as the response with either food or social contact with another pig as the reward. When they increased the "price" by making the pigs push the plate not just once but up to 30 times for each reward, they found that the pigs were willing to pay the higher price for food and worked harder and harder for the same number of rewards. By contrast, when social contact was the reward, they found that the pigs did not work as hard and thus obtained fewer rewards. Despite the difficulties that clearly exist with this approach (e.g., Dawkins 1990, 1997; Houston 1997; Mason et al. 1998), this method is still the only one that endeavors to show the animal's "point of view." Choice and reinforcement mechanisms thus occupy a very special place in the evaluation of animal welfare.

At the same time, however, it is important not to put too much emphasis on what animals may or may not find reinforcing. By now it will be quite clear that animals do not always act to benefit their fitness. This will be true even under natural conditions. For example, a migrating wildebeest may choose to cross a river, but then is eaten by a crocodile. On average, migration-including crossing rivers-is beneficial, but sometimes it isn't, even in natural environments (R Dawkins 1982). In unnatural environments, however, the likelihood of an animal choosing an option that lowers rather than raises its long-term fitness becomes much greater, because it is more likely to be confronted with a range of options for which it is not adapted. Its ancestors may have lived in environments in which absence of cover meant 
death by predation, and only those survived that remained hidden. Unnatural environments may also lead animals to make inappropriate choices. For example, an animal may find a sweet taste highly reinforcing because (in an adaptive sense) in its natural environment this preference led it to seek out fruit and honey. In a captive environment, however, the reinforcing properties of a sweet taste could lead it either to ingest nonnutritive saccharine or to overconsume freely available sucrose, neither of which would increase its fitness.

What animals find positively and negatively reinforcing should therefore not be used in isolation as a measure of welfare, any more than any other single measure should be. But knowing what animals find pleasurable or aversive often allows us to make sense of other measures such as physiological changes. What the animal prefers and will work for (or get away from) is thus not a luxury to be tagged on to other more "real" measurements such as physiological parameters, but is completely central to the proper evaluation of all welfare. It is what distinguishes animals and plants and gives rise to our moral concern for animal welfare. It helps us to make sense of other measures, and provides a framework in which they can be evaluated.

\section{CONCLUSIONS ABOUT}

\section{METHODS OF ASSESSMENT}

I have argued that applied welfare research stands to benefit greatly by becoming more Darwinian in its outlook. Essentially, this means pursuing the consequences of viewing the so-called indicators of welfare as adaptations to deal with threats to the animal's fitness, subject always to the proviso that adaptations can only be understood in the context of the environment in which they were evolved. To be more explicit, I will argue that the most practically useful and evolutionarily important measures of welfare fall into two categories: primary measures that are direct threats to fitness, and secondary ones that are perceived as threats to fitness.

Primary measures of welfare include such factors as injury, disease, exhaustion of muscle tissue, and dehydration. Here an animal's ability to survive and reproduce is directly reduced, in much the same way that a machine's ability to carry out its work is reduced if a part is broken or damaged. An injured animal's fitness is directly reduced, for instance, if it can no longer flee from predators. For this reason, I have stressed the importance of veterinary evidence about good or poor heal th as the first and essential measure of welfare. Animals have evolved a number of mechanisms, however, to avoid getting themselves into such dire straits in the first place. These include mobilizing the HPA system and changing their glucose metabolism so that they are better able to run away from danger; such mechanisms enable animals to avoid dangerous situations, and even play "Russian Roulette" with their immune systems, in the interests of reproduction. Such mechanisms-ones that come into play before (or to avoid) primary threats to fitness-can lead to secondary consequences.

Secondary measures of welfare or perceived threats to fitness may be activated when the animal's health is still good, and skeptics may then argue that there is no welfare problem, thus confusing the issue. Since the animal is behaving as if its fitness were threatened, however, and either taking or attempting avoidance actions, its welfare may be reduced just as much as if for a primary threat already evident. As Hofer and East (1998) put it: "Natural selection maximises fitness but not necessarily the well-being of organisms." A major problem, but no worse than that encountered by Nesse and Williams (1995) in their discussion of human medicine, is distinguishing between cases where the secondary mechanisms are effective (i.e., where the behavior or physiological mechanisms are the animal's way of dealing or coping with a danger) and where secondary mechanisms are ineffective and pathological. Clearly, intervention to "prevent suffering" is much more appropriate in the second case than in the first.

There are a number of important consequences of taking this Darwinian view of animal welfare:

1. High priority should always be given to primary threats to fitness (i.e., veterinary measures of welfare) since these have been major selective forces in the lives of all animals.

2. Individual secondary measures of welfare should not be judged to be "unreliable" just because they do not correlate 
consistently with primary measures. Animals usually have more than one kind of danger to avoid. They have complex tradeoffs at all levels in order to minimize reductions of fitness in facing a wide range of threats. At different times of the day or year, or depending on external circumstances, they will reallocate priorities: For example, animals may depress or enhance their immune responses, increase or decrease their physiological "stress" responses, or find some stimuli more or less aversive. Such changes should not be seen as a nuisance or inconsistent with primary measures (although they may well complicate the interpretation of an animal's welfare). Rather, they result from the complexity of an animal's adaptive response to various dangers.

3 . We should not expect that the response to all dangers should be the same. Given that the most adaptive response (at all levels in the body) may vary, depending on whether the danger is from dehydration, disease or predator attack, it is most unlikely that there will be a single measure of poor welfare, even a multicomponent one, that can be identified in all cases where the fitness of the animal is actually or potentially compromised. Rather, the responses of a given species should be studied separately when it meets threats of predation, dehydration, or absence of social companions. It may turn out, when the behavioral, physiological and biochemical data from these various situations are analysed and compared, that they will have a common component or syndrome of poor welfare that can be identified. This should be regarded as a fortunate and even somewhat surprising finding, however, and not something to be expected in advance.

4. Particular efforts should be made to identify the common components of situations that animals find aversive from those that they find pleasurable. No indicator of stress or poor welfare should be labeled as such unless it is clearly more than a symptom of excitement or readiness for action. In animals there is considerable overlap between preparation for action to gain something the animal wants, and preparation for action to escape something it finds aversive. The same limbs and muscles are used in both behaviors, together with the same energy needs. The difference is whether an animal decides that a given situation is positively or negatively reinforcing. Thus, particular emphasis should be given to an animal's own choice and reinforcement mechanisms; although these are not an infallible guide to welfare in themselves, they do allow us to make sense of all the other measures. They tell us what the animal finds rewarding or aversive. And by finding out how hard an animal will work to change its situation, we can learn something about the strength of its motivation to change. The finely tuned system of primary and secondary reinforcements that have evolved that enable animals to deal with the costs and benefits of different courses of action are a major secondary mechanism for avoiding primary threats to fitness. As such, they constitute both our best chance to view the way another species perceives its world and, ironically, a major source of poor welfare in themselves. If animals did not perceive various situations as "punishing," assessing their welfare would be quite easy.

Although insights from evolutionary biology can thus benefit applied animal welfare studies, other areas of biology can also benefit from some of the issues raised by animal welfare. Indeed, it could be argued that attempts to find valid ways of measuring welfare have thrown into sharp relief some important issues: how is behavior controlled, how do hormones such as corticosteroids function in the body, and how are animal decision-making mechanisms related to fitness in the long term?

Above all, issues of animal welfare force us to look at consciousness and its evolution. In almost all other areas of biology, questions about consciousness can be put to one side in the best behaviorist manner. Learning and reinforcement mechanisms (and even emotions) can be discussed independently of whether animals are consciously aware of what they are doing. But a concern for animal wel- 
fare does not permit such a convenient evasion. Our own consciousness is an ever-present reality. If we believe in the explanatory power of natural selection, we have at the very least to consider the possibility that consciousness evolved by natural selection. If so, it must either be a factor in the life of an organism, or be a most extraordinary epiphenomenon (Dawkins 1993). But if consciousness has phenotypic effects, it should be possible to find out what these are, and to discover what is different about organisms that possess it. This in turn leads to questions about how to find out which organisms have conscious experiences. Practical problems of animal welfare thus force a radical reevaluation of what constitute legitimate topics of biological research, as well as link diverse fields from molecular immunology to behavior, all of which contribute to the common goal of understanding the range of fitness-enhancing mechanisms that have evolved in animals. As a framework for a broadly based mechanistic biology, animal welfare is central to much of modern biology, even though "pure" biologists may not always realize it. All branches of biology are affected by the issues raised in animal welfare.

\section{The Connection Between WELFARE AND "SUFFERING"}

In a thoughtful and provocative essay, entitled "The myth of animal suffering," Bermond (1997) correctly points out that none of the methods proposed so far for assessing "suffering" in animals actually do so. "Suffering," as applied to humans, means conscious experience of something very unpleasant. Strictly speaking, none of the measures of "poor welfare" or "stress" discussed so far demonstrates the presence of comparable states in nonhuman animals. They could all be occurring in organisms without consciousness that are programmed in various ways to respond adaptively as far as the animal's fitness is concerned. As we have seen, adaptive responses to a range of stressors occur in plants as well as animals. Even measures that distinguish responses to danger in animals from those of plants-namely, the ability to show reinforced behavior-carry no necessary implications of conscious experience. Although there are striking similarities between the way rats and humans respond to certain situations such as hunger and cold (Cabanac 1992), it does not follow that both species are consciously experiencing hunger and cold. Even the fact that humans say they are consciously experiencing "suffering" from cold and then proceed to behave like rats in seeking warmth, does not mean that rats also consciously experience the same thing, tempting as it is to conclude that they do (Dawkins 1993). The reason why such a conclusion would be invalid is both instructive and subtle.

One of the findings that has emerged from recent neurophysiological research is the concept of "multiple routes to action"-the idea that the same action can be ordered by different parts of the brain, some of them giving rise to conscious experiences and others resulting in quite automatic responses when people report no conscious experiences (Rolls 1998). An obvious example is driving a car; sometimes we can be conscious of every action, and at other times we are effectively on "autopilot" and not conscious of what we are doing. The important point is that when our actions are under conscious control, we do not lose the unconscious pathways. On the contrary, we retain them, often reverting to them for routine actions that we have done many times before; we use the conscious pathways only for dealing with novel situations. Indeed, our conscious minds are often not as good at dealing with routine tasks as taking the unconscious route (Baars 1988). So the fact that we share many physiological mechanisms and behavioral responses with other species, particularly mammals, cannot be used as conclusive evidence that they share our conscious experiences, too. It would be possible to argue that they simply use the same neural pathways that we use for automatic, unconscious actions. They may possess many similarities to ourselves, but not that of shared conscious experiences. With a brain and an ability to think ahead ten years, you may decide to take out health insurance or make other provisions for the future. But this does not mean that your pain mechanisms or injury responses become redundant, or that you should stop avoiding situations that are likely to lead to injury. The death-defying, fitness-increasing mechanisms we share with other animals could simply have been 
augmented by a conscious ability to plan rationally for the future. The ability to avoid injury that we see in many species, through their fear or their ability to be aware of impending doom has enabled us to lessen the chances of fitness reduction or avoid danger entirely some weeks, months, or years before danger appears. The question is thus not whether there are similarities between humans and other species in responses to dangerous or aversive situations (because there clearly are), but which similarities are specifically relevant to the likelihood of shared conscious experiences.

Bermond himself argues that both a welldeveloped prefrontal cortex and a right neocortex structure are necessary and therefore that conscious emotional experiences are only to be expected in anthropoid apes and possibly dolphins. Such a hardware-dependent explanation assumes, of course, that conscious experiences are unique to particular brain structures, and ignores the possibility that in species very different from us, other brain pathways could give rise to consciousness by using different hardware. Even the determinedly Darwinian view that if consciousness evolved by natural selection it must have a detectable effect on some aspect of an animal's behavior or physiology, and do something to enhance fitness (Dawkins 1993), does not free us from this dilemma. If consciousness enhances existing danger-avoiding and reward-seeking mechanisms by enabling them to operate earlier and earlier, it is very difficult to see where unconscious learning mechanisms are replaced by conscious experiences. It might be that conscious experiences or qualia are present in many animals which "feel" hunger or fear in very much the way we do. But it could also be, for those who wish to take a hard line, that the basic physiological and behavioral mechanisms were in place and fully functional long before consciousness evolved, and all that consciousness did was to add an extra abil- ity to deal with longer time scales or greater complexity.

All this emphasizes that consciousness remains "the hard problem" of biology (Shear 1997). Easy (although often complex) problems are questions such as how animals discriminate different objects or how behavior is controlled. The hard problem is why, when we make a discrimination, it feels like anything at all. Why, in other words, does pain hurt?

The fact that we cannot yet solve the hard problem does not mean that we should rule out the possibility of including it some day in the science of animal welfare. The current state of animal welfare is the study of health, fitness and the various mechanisms animals have evolved for ensuring future health and fitness. Such studies can be carried out without any mention of the conscious experience of "suffering." But a complete science of animal welfare would include a consideration of the conscious experiences of animals, just as a complete study of biology would. To that extent, biology is incomplete, too. Animal welfare studies, by focusing on the feelings an animal might experience, have brought a whole new dimension to the study of animal consciousness, which otherwise emphasizes purely the intellectual achievements of animals as the key to understanding their consciousness (Griffin 1992; Bekoff and Jamieson 1996). Cognitive ethology emphasizes cognitive abilities, whereas in the context of animal welfare, emotions are more important. The often quoted phrase of Jeremy Bentham is relevant here: "The question is not Can they Reason?, nor Can they Talk? but Can they Suffer?" The question Bentham had in mind was that of which organisms deserve moral consideration, but it could equally well be used as to mean the question of which animals might possess consciousness. The key to the origin of consciousness itself may lie in the emotional experience of suffering (Dawkins 1993). 


\section{REFERENGES}

Andersen B L, Kiecolt-Glaser J K, Glaser K R. 1994. A biobehavioral model of cancer stress and disease course. American Psychologist 49:389-404.

Andreae U, Smidt D. 1982. Behavioral alterations in young cattle on slatted floor. In Disturbed Behaviorin Farm Animals: Seminar in the EEC Program of Coordination of Research on Animal Welfare at the University of Hohenheim, 1981, edited by W Bessei. Stuttgart: Ulmer.

Archer J. 1979. Animals under Stress. London: Edward Arnold.

Baars J. 1988. A Cognitive Theory of Consciousness. Cambridge: Cambridge University Press.

Barnard C J, Behnke J M, Sewell J. 1993. Social behaviour, stress and susceptibility to infection in house mice (Mus musculus): effects of duration of grouping and aggressive behaviour prior to infection on susceptibility to Babesia-microti. Parasitology 107:183-192.

Barnett J L, Hemsworth P H. 1990. The validity of physiological and behavioral measures of animal welfare. Applied Animal Behavior Science 25: 177-187.

Bateson P. 1991. Assessment of pain in animals. Animal Behaviour 42:827-839.

Bateson P, Bradshaw E L. 1997. Physiological effects of hunting red deer (Cervus elaphus). Proceedings of the Royal Society of London Series B 264:1707-1714.

Baxter M. 1983. Ethology in environmental design for animal production. Applied Animal Ethology 9:207-220.

Bekoff M, Byers J A. 1992. Time, energy and play. Animal Behaviour 44:981-986.

Bekoff M, Jamieson D. 1996. Readings in Animal Cognition. Cambridge (MA): MIT Press.

Bermond B. 1997. The myth of animal suffering. In Animal Consciousness and Animal Ethics: Perspectives from the Netherlands, edited by M Dol, S Kasamoentalib, S Lijmbach, E Rivas and $\mathrm{R}$ vanden Bos, pp 125-143. Assen (The Netherlands): Van Gorcum.

Brockmann H J. 1980. Control of nest depth in a digger wasp (Sphex ichneumoneus L.). Animal Behaviour 28:426-445.

Broom D M. 1991. Assessing welfare and suffering. Behavioural Processes 25:117-123.

Broom D M, Johnson K G. 1993. Stress and Animal Welfare. London: Chapman \& Hall.

Cabanac M. 1992. Pleasure: the common currency. Journal of Theoretical Biology 155:173-200.

Cannon W B. 1929. Bodily Changes in Pain, Hunger, Fear and Rage: An Account of Recent Researches into the Function of Emotional Excitement. Second Edition. New York: D. Appleton and Company.

Carlstead K. 1996. Effects of captivity on the behavior of wild mammals. In Wild Mammals in Captiv- ity: Principles and Techniques, edited by D G Kleiman, ME Allen, KV Thompson and S Lumpkin, pp 317-333. Chicago: University of Chicago Press.

Clutton-Brock T H, Guiness F E, Albon S D. 1982. Red Deer: Behavior and Ecology of Two Sexes. Edinburgh: University of Edinburgh Press.

Colborn D R, Thompson D L, Roth T L, Capehart J S, White K L. 1991. Responses of cortisol and prolactin to sexual excitement and stress in stallions and geldings. Joumal of Animal Science 69:2556-2562.

Craig J V, Craig J A, Vargas Vargas J. 1986. Corticosteroids and other indicators of hens' well-being in four laying house environments. Poultry Science 65:856-863.

Crick F. 1994. The Astonishing Hypothesis: The Scientific Search for the Soul. New York: Scribner Maxwell Macmillian International.

Cronin G M, Wiepkema P R, van Ree J M. 1985. Endogenous opioids are involved in abnormal stereotyped behaviors of tethered sows. Neuropeptides 6:527-530.

Cullen J M. 1966. Reduction of ambiguity through ritualization. Philosophical Transactions of The Royal Society of London Series B 251:363-374

Curtis SE. 1987. Animal well-being and animal care. Veterinary Clinics of North America-Food Animal Practice 3:369-382.

Dantzer R. 1991. Stress, stereotypies and welfare. Behavioural Processes 25:95-102.

Dantzer R, Mormède P. 1983. Stress in farm animals: a need for reevaluation. Journal of Animal Science 57:6-18.

Dawkins M S. 1980. Animal Suffering: The Science of Animal Welfare. London: Chapman \& Hall.

Dawkins M S. 1988. Behavioral deprivation: a central problem in animal welfare. Applied Animal Behavior Science 20:209-225.

Dawkins M S. 1990. From an animal's point of view: motivation, fitness and animal welfare. The $\mathrm{Be}-$ havioral and Brain Sciences 13:1-61.

Dawkins M S. 1993. Through Our Eyes Only?: The Search for Animal Consciousness. Oxford: W. H. Freeman/Spektrum.

Dawkins M S. 1997. Suffering, demand curves and welfare: a reply to Houston. Animal Behaviour 53:1119-1121.

Dawkins R. 1982. The Extended Phenotype: The Gene as the Unit of Selection. Oxford (Oxfordshire): W. H. Freeman.

Dennett D C. 1991. Consciousness Explained. New York: Little Brown and Co.

Duncan I J H. 1993. Welfare is to do with what animals feel. Jourmal of Agricultural and Environmental Ethics 6(supplement 2):8-14. 
Duncan IJ H. 1995. D. G. M. Wood-Gush Memorial Lecture: An applied ethologist looks at the question "Why?" Applied Animal Behavior Science 44: 205-217.

Duncan I J H. 1996. Animal welfare defined in terms of feelings. Acta Agriculturae Scandinavica Section A-Animal Science 27(supplement):29-35.

Duncan IJ H, Petherick J C. 1991. The implications of cognitive processes for animal welfare. Journal of Animal Science 69:5017-5022.

Duncan I J H, Wood-Gush D G M. 1972. Thwarting of feeding behavior in the domestic fowl. Animal Behaviour 20:444-451.

Eddy T J, Gallup G G, Jr. 1994. Passive socialization to humans: effects on tonic immobility in chickens (Gallus gallus). Animal Learning Eं Behavior 22: 325-331.

Edelman G M. 1992. Bright Air, Brilliant Fire: On the Matter of the Mind. London: Allen Lane.

Emlen S T, Wrege P H. 1989. A test of alternate hypotheses for helping behavior in white-fronted bee-eaters of Kenya. Behavioral Ecology Ẽ Sociobiology 25:303-319.

Fagen R. 1981. Animal Play Behavior. New York: Plenum Press.

Folstad I, Karter A J. 1992. Parasites, bright males, and the immunocompetence handicap. The American Naturalist 139:603-622.

Fraser A F, Broom D M. 1990. Farm Animal Behavior and Welfare. Third Edition. Wallingford (UK): CAB International.

Fraser D. 1995. Science, values and animal welfare: exploring the "inextricable connection." Animal Welfare 4:103-117.

Fraser D, Ritchie J S D, Fraser A F. 1975. The term "stress" in a veterinary context. British Veterinary Journal 131:653-662.

Fraser D, Weary D M, Pajor E A, Milligan B N. 1997. A scientific conception of animal welfare that reflects ethical concerns. Animal Welfare 6:187-205.

Freeman B M. 1985. Stress and the domestic fowl: physiological fact or fantasy? World Poultry Science Journal 41:45-51.

Gabrielsson G, Kanwisher J, Steen J B. 1977. "Emotional" bradycardia: a telemetry study on incubating willow grouse (Lagopus lagopus). Acta Physiologica Scandinavia 100:255-257.

Gibson S W, Hughes B O, Harvey S, Dun P. 1986. Plasma concentrations of corticosterone and thyroid hormones in laying fowls from different housing systems. British Poultry Science 27:621-628.

Godfray H C J. 1991. Signalling of need by offspring to their parents. Nature 352:328-330.

Gonyou H W. 1993. Animal welfare: definitions and assessment. Journal of Agricultural and Environmental Ethics 6(supplement 2):137-143.

Gregory N G, Wilkins L J. 1989. Broken bones in domestic fowl handling and processing damage in end-of-lay battery hens. British Poultry Science 30:555-562.

Griffin D R. 1992. Animal Minds. Chicago: University of Chicago Press.

Grossman C J. 1985. Interactions between the gonadal steroids and the immune system. Science 227:257-261.

Herrnstein RJ. 1977. The evolution of behaviorism. American Psychologist 32:593-603.

Hofer H, East M. 1998. Biological conservation and stress. In Advances in the Study of Behavior, edited by A P Møller, M Milinski and P J B Slater. San Diego (CA): Academic Press. In press.

Houston A I. 1997. Demand curves and welfare. Animal Behaviour 53:983-990.

Houston A I, MacNamara J M. 1988. A framework for the functional analysis of behavior. The Behavioral and Brain Sciences 11:117-163.

Hughes B O, Duncan I J H, Brown M F. 1989. The performance of nest building by domestic hens: is it more important than the construction of a nest? Animal Behavior 37:210-214.

Hurnik J F. 1993. Ethics and animal agriculture. Jourmal of Agricultural and Environmental Ethics 6(supplement 1):21-35.

Jarvis J U M, Oriain M J, Bennett N C, Sherman P W. 1994. Mammalian eusociality: a family affair. Trends in Ecology and Evolution 9(2):47-51.

Jones R B, Faure J M. 1981. Tonic immobility ("righting time") in laying hens housed in cages and pens. Applied Animal Ethology 7:369-372.

Kiley-Worthington M. 1989. Ecological, ethological and ethically sound environments for animals: towards symbiosis. Journal of Agricultural Ethics 2:323-347.

Koelkebeck K W, Amors M S, Cain J R. 1987. Production, physiological and behavioral responses of laying hens in different management environments. Poultry Science 66:392-407.

Lawrence A. 1987. Consumer demand theory and the assessment of animal welfare. Animal Behaviour 35:293-295.

Lawrence A B, Rushen J. 1993. Stereotypic Animal Behaviour: Fundamentals and Applications to Welfare. Wallingford (UK): CAB International.

Lawrence A B, Terlouw E M C. 1993. A review of behavioral factors involved in the development and continued performance of stereotypic behaviors in pigs. Joumal of Animal Science 71:2815-2825.

Lorenz K. 1950. The comparative method in studying innate behaviour patterns. Symposium of the Society for Experimental Biology 4:221-268.

Maestripieri D, Schino G, Aureli F, Troisi A. 1992. A modest proposal: displacement activities as an indicator of emotions in primates. Animal Behaviour 44:967-979. 
Maier S F, Watkins L R, Fleshner M. 1994. Psychoneuroimmunology: the interface between behavior, brain, and immunity. American Psychologist 49:1004-1017.

Markowitz H. 1982. Behavioral Enrichment in the Zoo. New York: Van Nostrand Reinhold.

Martin P, Caro T M. 1985. On the functions of play and its role in behavioral development. Advances in the Study of Behavior 15:59-103.

Mason G. 1991. Stereotypies: a critical review. Animal Behaviour 41:1015-1037.

Mason G. 1993. Forms of stereotypic behaviour. In Stereotypic Animal Behaviour, edited by J Rushen and A B Lawrence, pp 7-40. Wallingford (UK): $\mathrm{CAB}$ International.

Mason G, McFarland D, Garner J. 1998. A demanding task: using economic techniques to assess animal priorities. Animal Behaviour 55:in press.

Mason G, Mendl M. 1993. Why is there no simple way of measuring animal welfare? Animal Welfare 2:301-320.

Mason G, Turner M A. 1993. Mechanisms involved in the development and control of stereotypies. In Perspectives in Ethology, Volume 10, edited by P P G Bateson, P H Klopfer and N S Thompson, pp 53-85. New York: Plenum Press.

Matthews L, Ladewig J. 1994. Environmental requirements of pigs measured by behavioural demand functions. Animal Behaviour 47:713-719.

McCruden A B, Stimson W H. 1991. Sex hormones and immune function. In Psychoneuroimmunology, Second Edition, edited by R Ader, D L Felten and N Cohen, pp 275-294. San Diego (CA): Academic Press.

Mench J A, van Tienhoven A, Marsh J A, McCormick C C, Cunningham D L, Baker R C. 1986. Effects of cage and floor management on behavior, production and physiological stress responses of laying hens. Poultry Science 65:856-863.

Mendl M. 1991. Some problems with the concept of a cut-off point for determining when an animal's welfare is at risk. Applied Animal Behavior Science 31:139-146.

Moberg G P. 1987. Problems of defining stress in animals. Joumal of the American Veterinary Medical Association 191:1207-1211.

Moberg G P. 1993. Using risk assessment to define animal welfare. Jourmal of Agricultural and Environmental Ethics 6(supplement 2):1-7.

Møller A P, Sanotra G S, Vestergaard K S. 1995. Developmental stability in relation to population density and breed of chickens Gallus gallus. Poultry Science 74:1761-1771.

Møller A P, Swaddle J P. 1997. Asymmetry, Developmental Stability, and Evolution. Oxford: Oxford University Press.

Morton D B, Griffiths P H M. 1985. Guidelines on the recognition of pain, distress and discomfort in experimental animals and an hypothesis for assessment. Veterinary Record 116:431.

Nesse R M, Williams G C. 1995. Evolution and Healing: The New Science of Darwinian Medicine. London: Weidenfeld \& Nicolson.

Nestor KE. 1984. Genetics of growth and reproduction in the turkey: long-term selection for increased 16-week body weight. Poultry Science 63:2114-2122.

Olivier B, Molewijk E, van Oorschot R, van der Poel G. 1994. New animal models of anxiety. European Neuropsychopharmacology 4:93-102.

Parsons P A. 1990. Fluctuating asymmetry: an epigenetic measure of stress. Biological Reviews 65:131145.

Penrose R. 1994. Shadows of the Mind: A Search for the Missing Science of Consciousness. Oxford: Oxford University Press.

Rollin B E. 1995. Farm Animal Welfare: Social, Bioethical and Research Issues. Ames (IA): Iowa State University Press.

Rolls E T. 1990. A theory of emotion, and its application to understanding the neural basis of emotion. Cognition and Emotion 4:161-190.

Rolls E T. 1998. The Brain andEmotion. Oxford: Oxford University Press.

Rushen J. 1991. Problems associated with the interpretation of physiological data in the assessment of animal welfare. Applied Animal Behavior Science 28:381-386.

Rushen J, De Passillé A M B. 1992. The scientific assessment of the impact of housing on animal welfare: a critical review. Canadian Journal of Animal Science 72:721-744.

Sambraus H H. 1982. Ethologische Grundlagen einer tiergerechten Nutztierhaltung. Tierhaltung 13:23-41.

Sapolsky R M. 1994. Why Zebras Don't Get Ulcers: A Guide to Stress, Stress-Related Diseases and Coping. New York: W. H. Freeman.

Selye H. 1956. The Stress of Life. New York: McGrawHill Book Co.

Selye H. 1974. Stress without Distress. London: Hodder and Stoughton.

Shear J. 1997. Explaining Consciousness: The "Hard Problem." Cambridge (MA): MIT Press.

Sherry D F, Mrosovsky N, Hogan J A. 1980. Weight loss and anorexia during incubation in birds. Journal of Comparative and Physiological Psychology 94:89-98.

Stafleu F R, Grommers F J, Vorstenbosch J. 1996. Animal welfare: evolution and erosion of a moral concept. Animal Welfare 5:225-234.

Szechtman H, Lambrou P J, Caggiula A R, Redgate E S. 1974. Plasma corticosterone levels during sexual behavior in male rats. Hormones and $\mathrm{Be}$ havior 5:191-200. 
Tannenbaum J. 1991. Ethics and animal welfare: the inextricable connection. Journal of the American Veterinary Medical Association 198:1360-1376.

Thorpe W H. 1965. The assessment of pain and distress in animals. In Report of the Technical Committee to Enquire into the Welfare of Animals kept under Intensive Livestock Systems, edited by F W R Brambell. London: Her Majesty's Stationery Office.

Thorpe W H. 1969. Welfare of domestic animals. Nature 224:18-20.

Tinbergen N. 1951. The Study of Instinct. Oxford: Clarendon Press.

Tinbergen N. 1963. On aims and methods of ethology. Zeitschrift für Tierpsychologie 20:410-433.

Toates F M. 1995. Stress: Conceptual and Biological Aspects. New York: John Wiley \& Sons.

Vestergaard K. 1980. The regulation of dustbathing and other behavior patterns in the domestic hen: a Lorenzian approach. In The Laying Hen and its Environment: A Seminar in the EEC Programme of Coordination of Research on Animal Welfare, edited by R Moss, pp 101-120. The Hague: Martinus Hijhoff.

Vestergaard K, Kruijt J P, Hogan J A. 1993. Feather pecking and chronic fear in groups of red junglefowl: their relations to dustbathing, rearing environment and social status. Animal Behaviour 45:1127-1140.
Wall P. 1979. On the relation of injury to pain. Pain 6:253-264.

Weary D M, Fraser D. 1995. Calling by domestic piglets: reliable signals of need? Animal Behaviour 50:1047-1055.

Webster J. 1994. Animal Welfare: A Cool Eye towards Eden. Oxford: Blackwell Science.

Weipkema P, Koolhaas J M. 1993. Stress and animal welfare. Animal Welfare 2:195-218.

Weiskrantz L. 1997. Consciousness Lost and Found: A Neuropsychological Exploration. Oxford: Oxford University Press.

Wingfield J C, Hunt K, Breuner C, Dunlap K, Fowler G S, Freed L, Lepson J. 1997. Environmental stress, field endocrinology and conservation biology. In Behavioral Approaches to Conservation in the Wild, edited by J R Clemmons and R Buchholz, pp 95-131. Cambridge: Cambridge University Press.

Wolfensohn S, Lloyd M. 1994. Handbook of Laboratory Animal Management and Welfare. Oxford: Oxford University Press.

Wong-Valle J, McDaniel G R, Kuhlers D L, Bartels E. 1993. Correlated responses to selection for high or low incidence of tibial dyschondroplasia in broilers. Poultry Science 72:1621-1629.

Wood-Gush D G M. 1971. The Behaviour of the Domestic Fowl. London: Heinemann Educational. 